Since publication of his article, the author reports no further potential conflict of interest.

1. Kaki R, Elligsen M, Walker S, Simor A, Palmay L, Daneman N. Impact of antimicrobial stewardship in critical care: a systematic review. J Antimicrob Chemother 2011;66:1223-30.
2. Institute of Medicine. Redesigning the clinical effectiveness research paradigm: innovation and practice-based approaches: workshop summary. Washington, DC: National Academies Press, 2010.

\title{
Abiraterone and Increased Survival in Metastatic Prostate Cancer
}

TO THE EDITOR: De Bono et al. (May 26 issue) ${ }^{1}$ report that the CYP17 inhibitor abiraterone increased survival in patients with metastatic castration-resistant prostate cancer. However, CYP17 inhibition leads to a corticotropin-induced mineralocorticoid excess that needs to be efficiently counteracted. ${ }^{2}$ In this study, such hormone derangement was mitigated but not abolished by the concomitant administration of prednisone. A greater incidence of hypokalemia and fluid retention was seen in patients receiving abiraterone plus prednisone than in those receiving placebo plus prednisone, and this may have contributed to the greater cardiac toxicity observed. It would be interesting to know how the investigators managed these side effects and the results obtained. In particular, was the prednisone dose increased? Were mineralocorticoid-receptor blockers introduced? Because of its intrinsic mineralocorticoid activity, ${ }^{3}$ prednisone may be not the best drug to be used in this context, and the potential introduction of dexamethasone as an alternative should be discussed. ${ }^{2}$ Finally, the authors should discuss the utility of monitoring serum corticotropin levels during abiraterone treatment in order to adjust the supplementation therapy on an individual basis.

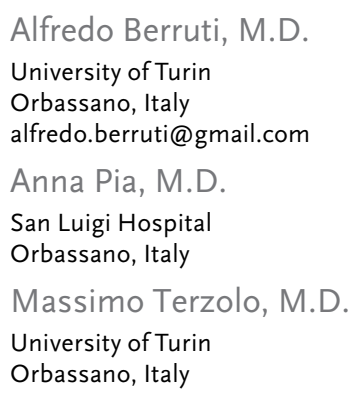

No potential conflict of interest relevant to this letter was reported.

1. de Bono JS, Logothetis CJ, Molina A, et al. Abiraterone and increased survival in metastatic prostate cancer. $\mathrm{N}$ Engl J Med 2011;364:1995-2005.

2. Miura K, Yasuda $\mathrm{K}$, Yanase $\mathrm{T}$, et al. Mutation of cytochrome P-45017 alpha gene (CYP17) in a Japanese patient previously reported as having glucocorticoid-responsive hyperaldosteronism: with a review of Japanese patients with mutations of CYP17. J Clin Endocrinol Metab 1996;81:3797-801.

3. Hindmarsh PC. Management of the child with congenital adrenal hyperplasia. Best Pract Res Clin Endocrinol Metab 2009; 23:193-208.

TO THE EDITOR: With the approval of cabazitaxel as a second-line therapy after the failure of docetaxel in patients with metastatic castrationresistant prostate cancer, it would be interesting to know the views of de Bono et al. on possible clinical measurements that might help in guiding the choice of cabazitaxel or abiraterone acetate. ${ }^{1}$ In their study, treatment was continued until disease progression on the basis of the prostate-specific antigen (PSA) level, radiographic imaging, and clinical findings. However, a clarification of whether abiraterone was discontinued for isolated PSA progression is necessary. Finally, the median progression-free survival (5.6 months) was substantially shorter than the median time to PSA progression (10.2 months) in the abiraterone group, which suggests a decoupling of PSA changes and antitumor activity. Did patients have objective progression in the context of PSA responses? Hence, should radiographic assessment be performed more frequently, or is a minimum of 12 weeks of therapy warranted before objective radiographic assessments in accordance with the recommendations of the Prostate Cancer Working Group 2? ${ }^{2}$

\section{Guru Sonpavde, M.D. \\ Texas Oncology \\ Houston, TX \\ guru.sonpavde@usoncology.com}

Dr. Sonpavde reports receiving lecture fees from Centocor Biotech, Sanofi-Aventis, and Dendreon and serving on an advisory board for Dendreon. No other potential conflict of interest relevant to this letter was reported.

1. de Bono JS, Oudard S, Ozguroglu M, et al. Prednisone plus cabazitaxel or mitoxantrone for metastatic castration-resistant prostate cancer progressing after docetaxel treatment: a randomised open-label trial. Lancet 2010;376:1147-54.

2. Scher HI, Halabi S, Tannock I, et al. Design and end points of clinical trials for patients with progressive prostate cancer and castrate levels of testosterone: recommendations of the 
Prostate Cancer Clinical Trials Working Group. J Clin Oncol 2008;26:1148-59.

TO THE EDITOR: In their editorial, Antonarakis and Eisenberger ${ }^{1}$ list no fewer than 21 completed and ongoing phase 3 trials of new agents in metastatic prostate cancer. We are surprised and disappointed at the omission of the Alpharadin in Symptomatic, Hormone-Refractory Prostate Cancer trial (ALSYMPCA; ClinicalTrials.gov number, NCT00699751). Radium-223 is a novel alphapharmaceutical that specifically targets bone metastases and has shown excellent efficacy and safety in a randomized phase 2 trial. $^{2}$ The omission of the ALSYMPCA trial is all the more unfortunate because since the editorial appeared, the trial has had a positive interim analysis for the overall survival end point. Radium-223 now joins a select list of just five drugs that have been shown to improve overall survival in patients with advanced prostate cancer.

Chris Parker, M.D.

Royal Marsden Hospital

Sutton, United Kingdom

chris.parker@rmh.nhs.uk

Oliver Sartor, M.D.

Tulane Cancer Center

New Orleans, LA

Dr. Parker reports receiving payment from Bayer for serving on an advisory board; and Dr. Sartor, receiving consulting fees from Algeta. No other potential conflict of interest relevant to this letter was reported.

1. Antonarakis ES, Eisenberger MA. Expanding treatment options for metastatic prostate cancer. N Engl J Med 2011;364: 2055-8.

2. Nilsson S, Franzén L, Parker C, et al. Bone-targeted radium-223 in symptomatic hormone-refractory prostate cancer. Lancet Oncology 2007;8:587-94.

DR. DE BONO AND COLLEAGUES REPLY: In response to the comments of Sonpavde: no data are available at this time to guide the sequencing of treatment for castration-resistant prostate cancer after the failure of docetaxel. We envision several scenarios: abiraterone administered with cabazitaxel from the outset, abiraterone given first, or cabazitaxel delivered first. This raises the key issue: Does cross-resistance between abiraterone and the taxanes exist? Preclinical data indicate that the taxanes have antitumor activity in this disease by affecting androgen-receptor signaling. ${ }^{1}$

Studies evaluating the tolerability and efficacy of the abiraterone-plus-cabazitaxel combination and randomized phase 3 trials evaluating the efficacy of different sequencing schedules are needed.

Practically, however, the patient's performance status, along with bone marrow and liver function, can guide further therapy. Moreover, pilot data have shown an association between pretreatment levels of plasma androgenic steroid hormone and ERG rearrangements and the response to abiraterone. ${ }^{2,3}$ Further studies of patient selection and molecular stratification are needed to optimize individual treatment.

Finally, patients were not discontinued from the abiraterone 301 trial because of PSA progression only. Also, progression-free survival was defined purely on the basis of radiologic data or death; the dichotomy between median time to PSA progression and radiologic progression-free survival may be due to the censoring of data for patients. It is important to note that flares that are seen on bone scans and computed tomography are common after treatment with abiraterone, and apparent worsening shown on these scans after treatment can be misleading. ${ }^{4,5}$

The incidence of toxic effects associated with CYP17 blockade by abiraterone acetate in our study was low, and such effects were easily managed by adequate doses of glucocorticoid or mineralocorticoid antagonists. Some steroidal mineralocorticoid antagonists, including spironolactone, can activate the androgen receptor and should not be used in patients with prostate cancer. Most patients did not require dose reduction; $3.8 \%$ of patients receiving abiraterone and $2.8 \%$ of those receiving placebo required increased doses of prednisone or prednisolone. Overall, $1.6 \%$ of patients receiving abiraterone and $1.8 \%$ of those receiving placebo received the mineralocorticoidreceptor antagonist eplerenone. However, further studies are warranted to evaluate whether different regimens (such as low-dose dexamethasone) can minimize both mineralocorticoid and iatrogenic glucocorticoid toxic effects. Dexamethasone was used with abiraterone in our trial using continuous doses of abiraterone. ${ }^{2}$

Johann S. de Bono, M.B., Ch.B., Ph.D.

Diletta Bianchini, M.D.

Andrea Zivi, M.D.

Institute of Cancer Research

Sutton, United Kingdom

Since publication of their article, the authors report no further potential conflict of interest.

1. Gan L, Chen S, Wang Y, et al. Inhibition of the androgen receptor as a novel mechanism of taxol chemotherapy in prostate cancer. Cancer Res 2009;69:8386-94. 
2. Attard G, Reid AH, A'Hern R, et al. Selective inhibition of CYP17 with abiraterone acetate is highly active in the treatment of castration-resistant prostate cancer. J Clin Oncol 2009;27:3742-8. 3. Attard G, Swennenhuis JF, Olmos D, et al. Characterization of ERG, AR, and PTEN gene status in circulating tumor cells from patients with castration-resistant prostate cancer. Cancer Res 2009;69:2912-8.
4. Ryan CJ, Shah SK, Efstathiou E, et al. Phase II study of abiraterone acetate in chemotherapy-naive metastatic castration-resistant prostate cancer displaying bone flare discordant with serologic response. Clin Cancer Res 2011 June 1 (Epub ahead of print). 5. Messiou C, Cook G, Reid AH, et al. The CT flare response of metastatic bone disease in prostate cancer. Acta Radiol 2011; 52:557-61.

\section{FOLFIRINOX versus Gemcitabine for Metastatic Pancreatic Cancer}

TO THE EDITOR: Conroy et al. (May 12 issue) ${ }^{1}$ report that FOLFIRINOX (a combination chemotherapy regimen consisting of oxaliplatin, irinotecan, fluorouracil, and leucovorin) provided a statistically and clinically significant benefit over single-agent gemcitabine in patients with advanced pancreatic cancer. Although the increased toxicity associated with this combination therapy may temper enthusiasm, this is the first real advance in such therapy since the introduction of gemcitabine. It has been debated whether gemcitabine-based combination therapies provide any additional benefit, and meta-analyses have reached conflicting conclusions..$^{2-4} \mathrm{~A}$ sensitivity analysis of data pooled from seven randomized trials involving 2422 patients in which single-agent gemcitabine was compared with gemcitabine in combination with cisplatin, oxaliplatin, or capecitabine indicates that the use of gemcitabine-based doublets had a clinically negligible, although statistically significant, absolute survival benefit (Table 1). However, power calculations reliably $(80 \%$ power, two-tailed alpha of 0.05 ) rule out the possibility that gemcitabine-based doublets could

\begin{tabular}{|c|c|c|c|c|c|c|c|c|}
\hline \multirow[t]{2}{*}{$\begin{array}{l}\text { Drug Combined } \\
\text { with Gemcitabine }\end{array}$} & \multirow[t]{2}{*}{$\begin{array}{l}\text { Randomized } \\
\text { Clinical Trials' }\end{array}$} & \multirow[t]{2}{*}{$\begin{array}{l}\text { No. of } \\
\text { Trials }\end{array}$} & \multirow[t]{2}{*}{$\begin{array}{l}\text { No. of } \\
\text { Patients }\end{array}$} & \multirow[t]{2}{*}{$\begin{array}{c}\text { Hazard Ratio } \\
(95 \% \mathrm{CI})\end{array}$} & \multicolumn{2}{|c|}{ P Value } & \multirow[t]{2}{*}{$\begin{array}{l}\text { Absolute } \\
\text { Difference } \\
\text { at } 1 \mathrm{Yr}(\%)\end{array}$} & \multirow[t]{2}{*}{$\begin{array}{l}\text { No. Needed } \\
\text { to Treat: }\end{array}$} \\
\hline & & & & & $\begin{array}{l}\text { Between-Group } \\
\text { Comparison }\end{array}$ & Heterogeneity & & \\
\hline Cisplatin & $\begin{array}{l}\text { Colucci et al. (2002) } \\
\text { Heinemann et al. } \\
\text { Colucci et al. (2010) }\end{array}$ & 3 & 702 & $0.94(0.76-1.17)$ & 0.61 & 0.19 & NA & NA \\
\hline Oxaliplatin & $\begin{array}{l}\text { Louvet et al. } \\
\text { Poplin et al. }\end{array}$ & 2 & 868 & $0.86(0.74-0.99)$ & 0.04 & 0.65 & 2.6 & $38-39$ \\
\hline Capecitabine & $\begin{array}{l}\text { Cunningham et al. } \\
\text { Herrmann et al. }\end{array}$ & 2 & 852 & $0.86(0.75-0.99)$ & 0.04 & 0.94 & 3.0 & $33-34$ \\
\hline Total & & 7 & 2422 & $0.87(0.80-0.96)$ & 0.005 & 0.53 & 2.3 & $43-44$ \\
\hline
\end{tabular}

* NA denotes not applicable.

$\uparrow$ Included in the meta-analysis were the following studies: Colucci G, Giuliani F, Gebbia V, et al. Gemcitabine alone or with cisplatin for the treatment of patients with locally advanced and/or metastatic pancreatic carcinoma: a prospective, randomized phase III study of the Gruppo Oncologia dell'Italia Meridionale. Cancer 2002;94:902-10; Heinemann V, Quietzsch D, Gieseler F, et al. Randomized phase III trial of gemcitabine plus cisplatin compared with gemcitabine alone in advanced pancreatic cancer. J Clin Oncol 2006;24:3946-52; Colucci G, Labianca R, Di Costanzo F, et al. Randomized phase III trial of gemcitabine plus cisplatin compared with single-agent gemcitabine as firstline treatment of patients with advanced pancreatic cancer: the GIP-1 study. J Clin Oncol 2010;28:1645-51; Louvet C, Labianca R, Hammel $P$, et al. Gemcitabine in combination with oxaliplatin compared with gemcitabine alone in locally advanced or metastatic pancreatic cancer: results of a GERCOR and GISCAD phase III trial. J Clin Oncol 2005;23:3509-16; Poplin E, Feng Y, Berlin J, et al. Phase III, randomized study of gemcitabine and oxaliplatin versus gemcitabine (fixed-dose rate infusion) compared with gemcitabine (30-minute infusion) in patients with pancreatic carcinoma E6201: a trial of the Eastern Cooperative Oncology Group. J Clin Oncol 2009;27:3778-85. [Erratum, J Clin Oncol 2009;27:5859.]; Cunningham D, Chau I, Stocken DD, et al. Phase III randomized comparison of gemcitabine versus gemcitabine plus capecitabine in patients with advanced pancreatic cancer. J Clin Oncol 2009;27:5513-8; Herrmann R, Bodoky G, Ruhstaller T, et al. Gemcitabine plus capecitabine compared with gemcitabine alone in advanced pancreatic cancer: a randomized, multicenter, phase III tria of the Swiss Group for Clinical Cancer Research and the Central European Cooperative Oncology Group. J Clin Oncol 2007;25:2212-17.

$\uparrow$ The number needed to treat refers to the number of patients who would need to be treated with the combination therapy for one patient to benefit in terms of outcome. 